\title{
Complementary chromatic adaptation alters photosynthetic strategies in the cyanobacterium Calothrix
}

\author{
Douglas Campbell
}

Department of Plant Physiology, University of Umeå, S-901-87 Umeå, Sweden
Tel: +4690165289. Fax: +4690166676 . e-mail: douglas.campbel1@plantphys.umu.se

Keywords: chlorophyll fluorescence, light-harvesting, phycobiliproteins, state transition

\section{INTRODUCTION}

Various cyanobacteria strongly modulate the composition of the rods of their phycobilisomes in response to the relative levels of red and green light. This acclimation process is termed complementary chromatic adaptation (CCA). The molecular mechanism for the red/green light regulation of CCA receives considerable attention (reviewed by Grossman, 1990; Grossman et al., 1994; Tandeau de Marsac et al., 1988; Tandeau de Marsac \& Houmard, 1993), particularly in the strain Calothrix sp.

\footnotetext{
Abbreviations: CCA, complementary chromatic adapatation; $\mathrm{Chl}$ a, chlorophyll a; $F_{0}$, minimal fluorescence; $F_{M}$ (dark), maximal fluorescence in the dark-adapted state; $F_{s}$, steady-state fluorescence under illumination; $F_{0}{ }^{\prime}$, minimum fluorescence in a light-adapted state; $F_{M}{ }^{\prime}$, maximal fluorescence in a light-adapted state; $F_{M}$ true maximal fluorescence; PS I, photosystem I; PS II, photosystem II; $q_{N}$, non-photochemical quenching of chlorophyll fluorescence; $q_{p}$, photochemical quenching of chlorophyll fluorescence.
}

PCC 7601 (Calothrix 7601, syn. Fremyella diplosiphon) (Bennett \& Bogorad, 1973; Capuano et al., 1988; Gendel et al., 1979; Grossman et al., 1988; Oelmüller et al., 1988a, b) and the closely related Tolypothrix tenuis (Fujita \& Hattori, 1960; Hattori \& Fujita, 1959a, b). Tandeau de Marsac (1983) distinguished three functional groups of cyanobacteria with respect to CCA. Calothrix is a representative of group 3, with the synthesis of both phycocyanin and phycoerythrin under chromatic control. A putative photoreversible pigment responds to red and green light, and regulates the expression of the phycoerythrin and phycocyanin-II operons through a system involving reversible phosphorylation of DNA-binding proteins, some of which have been characterized (Schmidt-Goff \& Federspiel, 1993; Schyns et al., 1994; Sobczyk et al., 1993, 1994). Under pure green light, phycoerythrin gene expression is induced and expression of phycocyanin II genes is nearly completely repressed (Mazel et al., 1986). Under red light the opposite occurs, with repression of phycoerythrin synthesis and induction 
of phycocyanin-II. Pigment content under white light falls between these extremes and depends on the balance of green and red in the light source (Tandeau de Marsac, 1983).

In Calothrix, CCA interacts with nitrogen metabolism and hormogonium differentiation in a complex regulatory network. On top of the light quality regulation, the environmental source of nitrogen modulates pigment content to favour phycoerythrin when nitrate is supplied, or phycocyanin if ammonium is supplied (Erokhina, 1992; Liotenberg et al., 1996). Futhermore, the pigment composition of the cells helps determine their susceptibility to induction of hormogonium differentiation (Damerval et al., 1991). This link apparently arises because differentiation can be triggered by imbalances in electron transport, which depend upon the light qualities captured by the pigment systems (Campbell et al., 1993). Furthermore, during differentiation all phycobiliprotein gene expression is transiently repressed (Damerval et al., 1991).

In spite of the long-term efforts to define the molecular elements involved in cyanobacterial CCA (Grossman et al., 1994; Kehoe \& Grossman, 1996; Houmard et al., 1996), functional characterization of the significance of CCA to photosynthesis has been lacking. Indeed, some ecologically oriented workers regard the phenomenon as a manifestation of low-light acclimation, with limited relevance to natural populations (Dring, 1981, 1990; Dring et al., 1996; reviewed by Wyman \& Fay, 1987). The dialogue is complicated by differing applications of the term CCA. In the original ecological sense, CCA referred to depth- and illumination-dependent segregation of algal groups according to pigmentation differences. This concept, although widely cited, has not withstood critical examination (Dring, 1981). In contrast, in many cyanobacteria, predominantly colonial or benthic strains from fresh water (Rippka \& Herdman, 1992), chromatic regulation of gene expression qualitatively alters phycobilisome composition (Dring, 1981; Tandeau de Marsac, 1983). This CCA process is quite distinct from the overall regulation of phycobiliprotein content, which involves the allophycocyanin and phycocyanin-I operons as well as phycoerythrin and phycocyanin-II. CCA in cyanobacteria is of interest not only as an example of chromatic regulation of gene expression, but also for photosynthetic studies because it allows drastic and reproducible manipulation of pigment content and overall absorbance within a single strain.

In this study I used three complementary approaches to characterize photosynthesis of Calotbrix 7601 cells acclimated to red or green light, measured under their growth light quality but also immediately after a shift to the alternative light quality. Oxygen evolution was used to monitor the rate and light-response of electron transport. Room-temperature fluorescence quenching analysis and $77 \mathrm{~K}$ fluorescence emission spectra provided information on the balance of electron transport and excitation between PS II and PS I. These results provide a functional characterization of CCA, and demonstrate alternate light-harvesting strategies and changes in electron transport upon changes in light quality.

\section{METHODS}

Cell growth. Cultures of Calothrix 7601 were grown in flat Roux bottles in $300 \mathrm{ml} \mathrm{BG} 11$ medium (Rippka et al., 1979) buffered to $\mathrm{pH} 7.5$ with $10 \mathrm{mM}$ MOPS, and bubbled with $1 \%$ $\mathrm{CO}_{2}$ in air at about $1 \mathrm{ml} \mathrm{s}^{-1}$. The Roux bottles were laid on their side in a Plexiglas shaking water bath regulated at $27^{\circ} \mathrm{C}$, with fluorescent and incandescent light sources shining up from below. The lower sides of the bottles were wrapped in red or green coloured filters (for spectra see Fig. 1), with the rest of the bottles wrapped in aluminium foil to exclude extraneous light. For both red- and green-light cultures the light intensity was about $15 \mu \mathrm{mol} \mathrm{m} \mathrm{m}^{-2} \mathrm{~s}^{-1}$. Cultures were inoculated with $10 \mathrm{ml}$ from axenic precultures and then grown for 6-7 d, at which point samples were taken for pigment, fluorescence and oxygen evolution analysis. No clumping occurred and in all cases the cultures contained only long, cylindrical filaments with no hormogonia or pro-heterocysts.

Sampling and pigments. Fifteen-millilitre samples were taken from the culture flasks. One millilitre was mixed with $9 \mathrm{ml}$ methanol to form a $90 \%$ methanolic extract for chlorophyll assays, while $13 \mathrm{ml}$ were loaded directly into the measurement cuvette, along with $100 \mu \mathrm{l} 1 \mathrm{M} \mathrm{NaHCO}_{3}$, added to ensure the culture did not become $\mathrm{CO}_{2}$ limited during the measurement. Each point presented on the graphs is the mean of three measurements on the same culture. The entire oxygen and room temperature fluorescence experiment was repeated three times on independently grown cultures, with similar results in all three replicates. Chlorophyll $a(\mathrm{Chl} a)$ content was measured as the absorbance at $665 \mathrm{~nm}$ of methanolic extracts of cells, using the equation 13.9 $\mu \mathrm{g} \mathrm{Chl} a \equiv 1 A_{665}$ unit (Tandeau de Marsac \& Houmard, 1988). The cultures contained 3-4.7 $\mu \mathrm{g} \mathrm{Chl} a \mathrm{ml}^{-1}$. Whole-cell spectra of typical red- and green-light grown cells were measured using a Shimadzu MPS 2000 dual-beam scanning spectrophotometer.

Oxygen measurements. The measurement cuvette used (Hansatech) allows precise control of light and temperature for simultaneous measurement of oxygen consumption or evolution, with a Clark-type electrode (Hansatech), and of fluorescence, with a PAM fluorometer (Walz) (Campbell et al., 1996; Clarke et al., 1993, 1995). Samples were first incubated in the dark to measure dark respiration. Then a Bjorkmann-type lamp (Hansatech) was used with filter combinations to provide increasing levels of green or red light to the culture. Measurement of the rate of oxygen evolution at seven to nine light intensities took about $40 \mathrm{~min}$ overall.

Room temperature fluorescence. When a pigment absorbs the energy of a photon and enters an excited state, there are essentially four routes for a return to the ground state: (1) photochemical reactions; (2) heat dissipation; (3) transfer of the energy to another pigment; and (4) emission of a fluorescence photon. These four processes are in competition, such that the most rapid de-excitation pathway predominates. For biological systems the chlorophyll fluorescence yield is usually very low (less than $3 \%$ of absorbed photons re-emitted as fluorescence), and, in vivo, fluorescence from PS II predominates (Krause \& Weis, 1991), although in cyanobacteria non-variable fluorescence from phycobiliproteins also strongly contributes (Campbell et al., 1996). Fluorescence, although a minor deexcitation pathway, is in competition with the quantitatively more important routes of photochemistry, transfer and heat dissipation. Therefore changes in the rates of photochemistry or in the two non-photochemical dissipation routes (transfer or heat) can alter (quench) the fluorescence yield from PS II (Bolhàr-Nordenkampf \& Öquist, 1993; Krause \& Weis, 1991). Minimum fluorescence, $\mathrm{F}_{0}$, was determined by illuminating the 
dark-adapted cells with a low-intensity light modulated at $1.6 \mathrm{kHz}$ (average intensity of $0.14 \mu \mathrm{mol}$ photons $\mathrm{m}^{-2} \mathrm{~s}^{-1}$ ) from a light-emitting diode (peak emission $650 \mathrm{~nm}$ ). A $1 \mathrm{~s}$ flash of saturating white light $\left(8000 \mu \mathrm{mol}\right.$ photons $\left.\mathrm{m}^{-2} \mathrm{~s}^{-1}\right)$ was then given to determine maximal fluorescence in the dark-adapted state, $F_{M}$ (dark). After a further $30 \mathrm{~s}$, the actinic light was activated. Steady-state fluorescence, $F_{\mathrm{s}}$, was achieved within $2 \mathrm{~min}$, and minimum fluorescence in the light-adapted state, $\mathrm{F}_{0}{ }^{\prime}$, was measured by briefly interrupting the actinic beam. After $\mathrm{F}_{\mathrm{s}}$ was re-established, a saturating light pulse was given to determine maximal fluorescence in the light-adapted state, $\mathrm{F}_{\mathrm{M}}{ }^{\prime}$. The actinic light intensity was then increased and the process was repeated in steps. Finally, 3-(3,4-dichlorophenyl)-1,1dimethylurea (DCMU) $(0.5 \mu \mathrm{M}$ final) was injected into the cuvette to stop electron transport, for determination of the true maximal fluorescence, $\mathrm{F}_{\mathrm{M}}$. The parameters $\mathrm{F}_{0}, \mathrm{~F}_{\mathrm{M}}$ (dark), $\mathrm{F}_{\mathrm{S}}, \mathrm{F}_{0}{ }^{\prime}$, $\mathrm{F}_{\mathrm{M}}{ }^{\prime}$ and $\mathrm{F}_{\mathrm{M}}$ were used for calculation of photochemical $\left(q_{\mathrm{P}}\right)$ and non-photochemical $\left(q_{\mathrm{N}}\right)$ quenching coefficients (van Kooten \& Snel, 1990).

$q_{\mathrm{P}}$ is approximately equal to the proportion of PS II reaction centres which are open and ready to perform photochemistry. It reflects the balance between capture of light energy, which tends to close the reaction centres, and dissipation of energy (by any route), which re-opens reaction centres. The non-photochemical quenching coefficient, $q_{\mathrm{N}}$, reflects any process other than photochemistry which lowers the fluorescence yield, and therefore is a measure of the transfer or heat dissipation deexcitation routes.

$77 \mathrm{~K}$ fluorescence emission spectra. Fifty-millilitre samples of the same cultures as used for oxygen and fluorescencequenching measurements were harvested and concentrated to 12.1-12.5 $\mu \mathrm{g} \mathrm{Chl} a \mathrm{ml}^{-1}$ by centrifugation. Thirteen millilitres were loaded into the cuvette used for oxygen and fluorescencequenching measurements. The sample was dark-adapted for $10 \mathrm{~min}$, and then, under very dim ambient light, a clear acrylic rod sample holder for $77 \mathrm{~K}$ fluorescence was dipped briefly into the cuvette to collect about $100 \mu \mathrm{l}$; this sub-sample was plunged directly into liquid nitrogen. The sample holder was attached to a fibre-optic-based fluorometer and $77 \mathrm{~K}$ fluorescence emission spectra were collected as described by Ogren \& Oquist (1984), with excitation at 430 and $574 \mathrm{~nm}$. The sample in the cuvette was then incubated under green or red light light equivalent to the growth light intensity of $15 \mu \mathrm{mol}$ photons $\mathrm{m}^{-2} \mathrm{~s}^{-1}$ and subsampling for $77 \mathrm{~K}$ fluorescence was repeated. Through this procedure, the $77 \mathrm{~K}$ spectra are from cells under precisely the same conditions as those used for room-temperature fluorescence quenching and oxygen measurements.

\section{RESULTS}

\section{Different pigmentation of cells grown under red and green light}

The transmission spectra of the red or green filters used for growth and photosynthetic measurements are presented in Fig. 1. After $6 \mathrm{~d}$ growth under $15 \mu \mathrm{mol}$ photons $\mathrm{m}^{-2} \mathrm{~s}^{-1}$ of either red or green light, the cultures reached similar cell densites of about $4 \mu \mathrm{g} C h l a \mathrm{ml}^{-1}$, although the whole-cell absorbance spectra presented in Fig. 2 show that the phycobiliprotein composition of the red-and green-light cultures was very different. The cultures grown under red light contained large amounts of phycocyanin, with a peak absorbance at $622 \mathrm{~nm}$, but only a trace of phycoerythrin. In contrast, the green-light cultures contained much less phycocyanin but had high

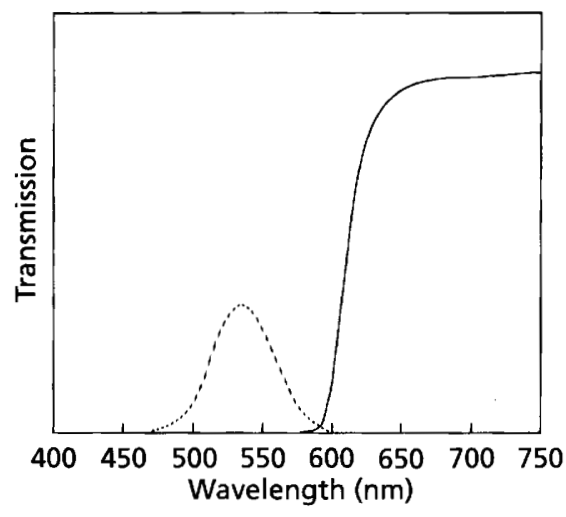

Fig. 1. Transmission spectra of the red ( $\longrightarrow$ ) or green ('"'in) coloured filters used for growth and photosynthetic measurements of the Calothrix PCC 7601 cultures.

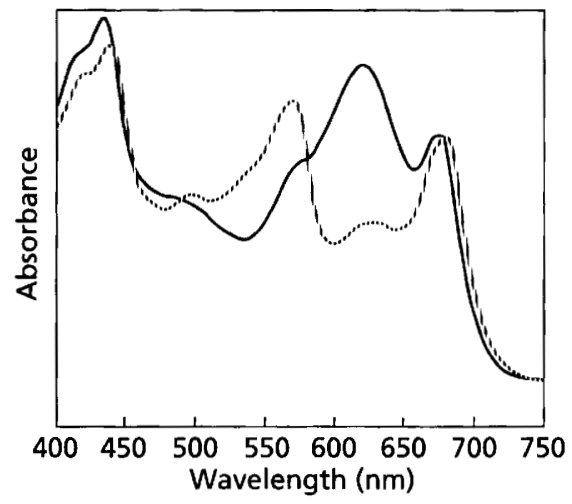

Fig. 2. Representative whole-cell absorbance spectra of Calothrix PCC 7601 cultures grown under red $(-)$ or green ('ii!) light.

levels of phycoerythrin, with peak absorbance at $568 \mathrm{~nm}$. Comparison of the spectra of the growth lights and the whole-cell spectra shows that the overlapping absorbance peaks of both phycocyanin and chlorophyll fall within the wavelength range of the red light supply, which transmits wavelengths greater than $605 \mathrm{~nm}$. In contrast, only phycoerythrin absorbance is appropriate for capture of the green light supply, peaking at $533 \mathrm{~nm}$.

\section{Similar oxygen evolution in cells grown under red or green light}

The light response curves of oxygen evolution were measured for cultures grown under red (Fig. 3a) or green (Fig. 3b) light. Oxygen evolution was measured under both red and green light, so that each culture was measured under the light quality used for its growth, but also under the alternative light quality. When oxygen evolution is plotted versus the supplied light intensity, the initial slope of the curve is proportional to the quantum yield of photosynthetic oxygen evolution. As the light intensity exceeds the level to which the cultures are 

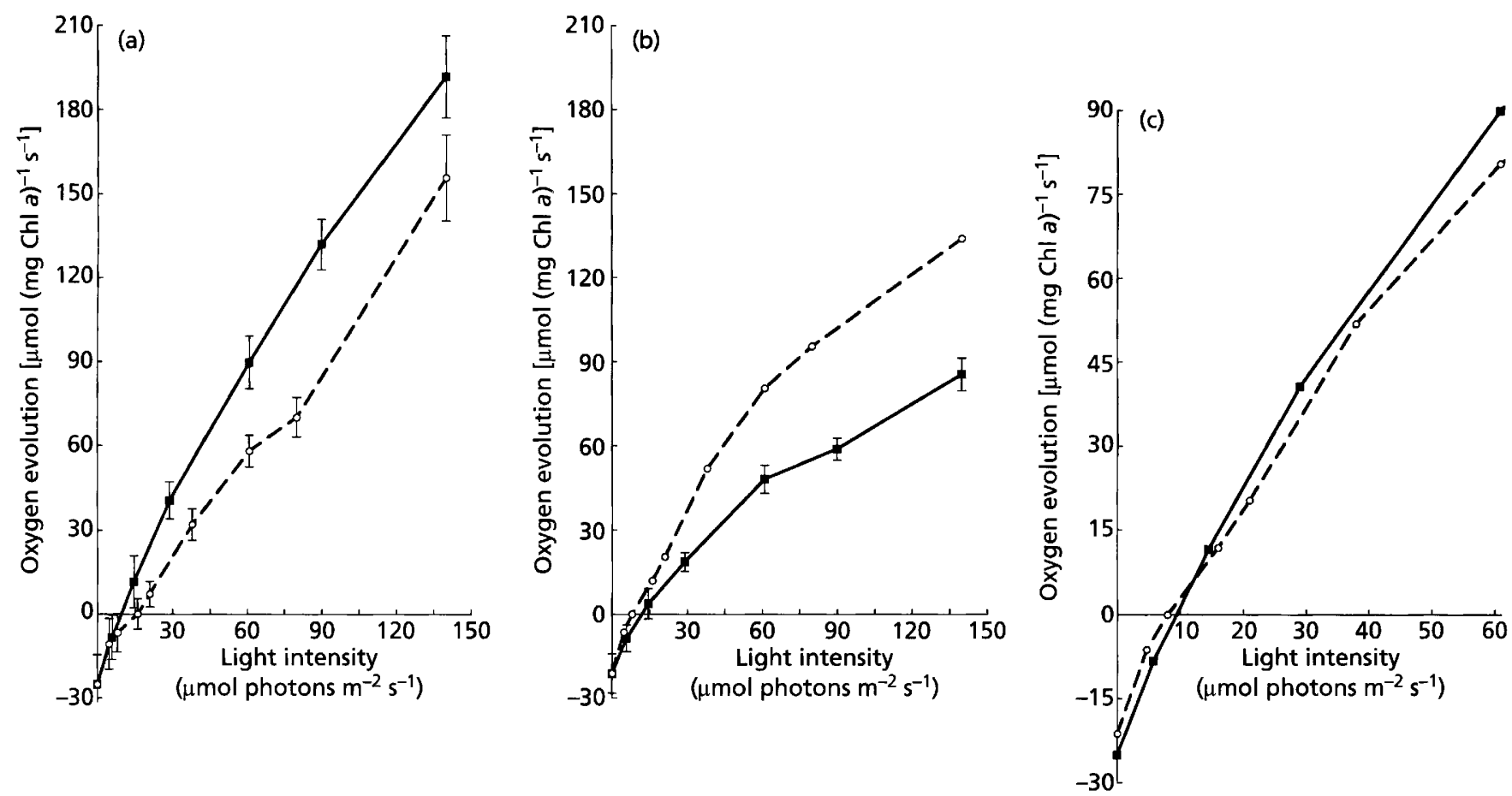

Fig. 3. Light response curves for oxygen evolution measured with red (- - ) or green $\left(-\mathrm{O}_{--}\right)$light. The results are means of three measurements on the same culture, \pm SE. (a) Culture grown under red light; (b) culture grown under green light. (c) Similar oxygen evolution at low light intensities for cultures measured under the light quality used for their growth, red (- - or green (--O--).

acclimated, the curve deviates below the initial slope, since factors other than light supply start to limit photosynthetic oxygen evolution. In these experiments the light intensities were not raised to levels high enough to saturate electron transport, in order to avoid any photoinhibition of the cells or changes in light quality at high intensity. The initial slopes, and hence the quantum yield of photosynthetic electron transport, were almost identical for red- and green- light-acclimated cultures when measured under their respective growth lights (Fig. $3 c$ ). Therefore, when a culture is properly acclimated the overall light-use efficiency of net photosynthetic electron transport is similar under green and red light.

Shifts of cells acclimated to red growth light to green measurement light, or vice versa, from green growth light to red measurement light, had similar effects on oxygen evolution. After either light shift the quantum yield of photosynthetic electron transport dropped to about $60 \%$ of the value under the respective growth light. This drop drove up the light compensation point from $9 \mu \mathrm{mol}$ photons $\mathrm{m}^{-2} \mathrm{~s}^{-1}$ for cells under their growth light quality to $15 \mu \mathrm{mol}$ photons $\mathrm{m}^{-2} \mathrm{~s}^{-1}$ (upon a shift of red light cells to green light) or to $12.5 \mu \mathrm{mol}$ photons $\mathrm{m}^{-2} \mathrm{~s}^{-1}$ (upon a shift of green light cells to red light) (Fig. 3a, b). Since the cells were acclimated to growth under only $15 \mu \mathrm{mol}$ photons $\mathrm{m}^{-2} \mathrm{~s}^{-1}$ these changes in the light compensation point and quantum yield have major influences on photosynthesis after a shift from one light quality to the other.

\section{PS II reaction centres remain largely open under red or green light}

For cultures grown under either red or green light, photochemical quenching of fluorescence, $q_{\mathrm{P}}$, is somewhat lower when measured under green light than when measured under red light (Fig. 4a, b). This difference is particularly evident for the cultures grown under red light and shifted to green light (Fig. 4a). However, in common with other cyanobacteria, $q_{\mathrm{P}}$ remained high even at light intensities 10-fold higher than the growth light intensity of $15 \mu \mathrm{mol}$ photons $\mathrm{m}^{-2} \mathrm{~s}^{-1}$ (Fig. $4 \mathrm{a}, \mathrm{b}$ ). This indicates that most PS II reaction centres $(>85 \%)$ remained open under all conditions, whereas in plants PS II centres close more readily in response to increasing light (Öquist $e t$ al., 1995).

\section{Energy transfer from the phycobilisome/PS II to PS I under green light}

Fig. 5 presents light response curves for $q_{\mathrm{N}}$, a measure of the non-photochemical quenching of fluorescence. In these Calotbrix 7601 cultures, as in most cyanobacteria, $q_{\mathrm{N}}$ was relatively high in dark-acclimated cells, reflecting state II, a condition of low PS II fluorescence yield. Generally, upon illumination PS II fluorescence yield increases and $q_{\mathrm{N}}$ drops, falling to a minimum at around the growth light intensity, as the cells enter state I (Fujita et al., 1994). This typical pattern of a state II to state I transition was very pronounced in the Calotbrix 7601 


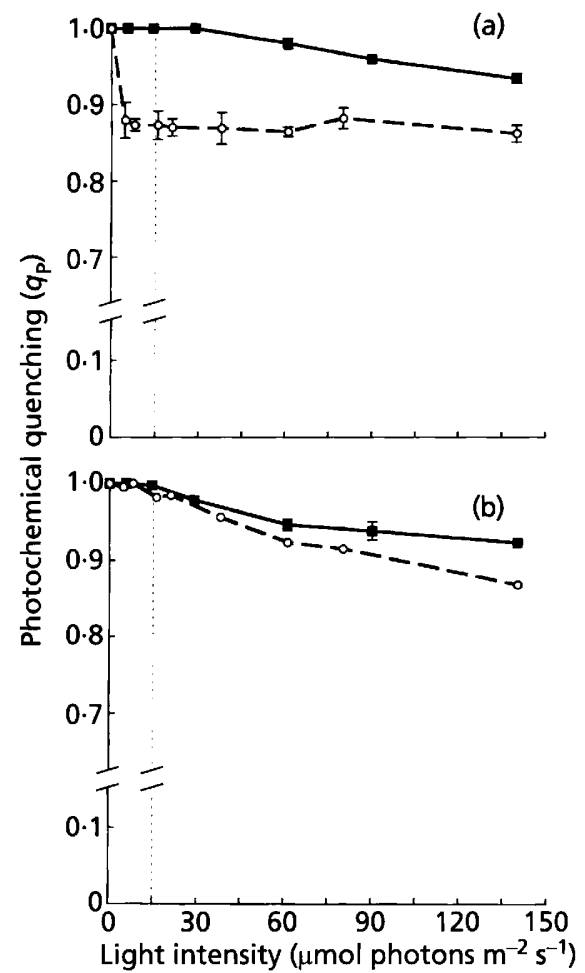

Fig. 4. Light response curves of photochemical quenching measured under red (- - ) or green (- $\mathrm{O}_{--}^{-}$) light. The dashed vertical line marks the growth light intensity $(15 \mu \mathrm{mol}$ photons $\mathrm{m}^{-2} \mathrm{~s}^{-1}$ ). The results are means of three measurements on the same culture, \pm SE. (a) Culture grown under red light; (b) culture grown under green light.

cultures upon illumination with red light (Fig. 5a, b). In contrast, under green illumination $q_{\mathrm{N}}$ remained high, at or near the dark-acclimated level, for cultures grown under either light. There was little evidence of a state II-state I transition under green light and the cells remained in state II throughout the light-response curve (Fig. 5a, b). Nevertheless, cells grown under green light were fully competent to perform a large state transition when shifted to red light (Fig. 5b).

Fig. 6 presents $77 \mathrm{~K}$ fluorescence emission spectra for cells after pre-incubation in the dark or after preincubation under $15 \mu \mathrm{mol}$ photons $\mathrm{m}^{-2} \mathrm{~s}^{-1}$ of red or green light. Cells were pre-treated in the same cuvette and in the same manner as for the room-temperature fluorescence measurements used for calculation of $q_{\mathrm{P}}$ (Fig. 4) and $q_{\mathrm{N}}$ (Fig. 5). Excitation of fluorescence was with 569-579 nm light, absorbed by the phycobilisome. The major emission peaks were from PS I $(726-729 \mathrm{~nm})$; PS II $(682-685 \mathrm{~nm}$, shoulder at 690-693 nm); phycocyanin $(655-659 \mathrm{~nm})$ and phycoerythrin $(642-647 \mathrm{~nm})$. In the single-celled cyanobacterium Synechococcus sp. strain PCC 7942 the PS II fluorescence is resolved into two clear peaks (Salehian \& Bruce, 1992), whereas in Calothrix 7601 the $690 \mathrm{~nm}$ fluorescence is only a shoulder. Whether this difference represents an important distinction in fluorescence emission from PS II, or if it arises simply from less favourable

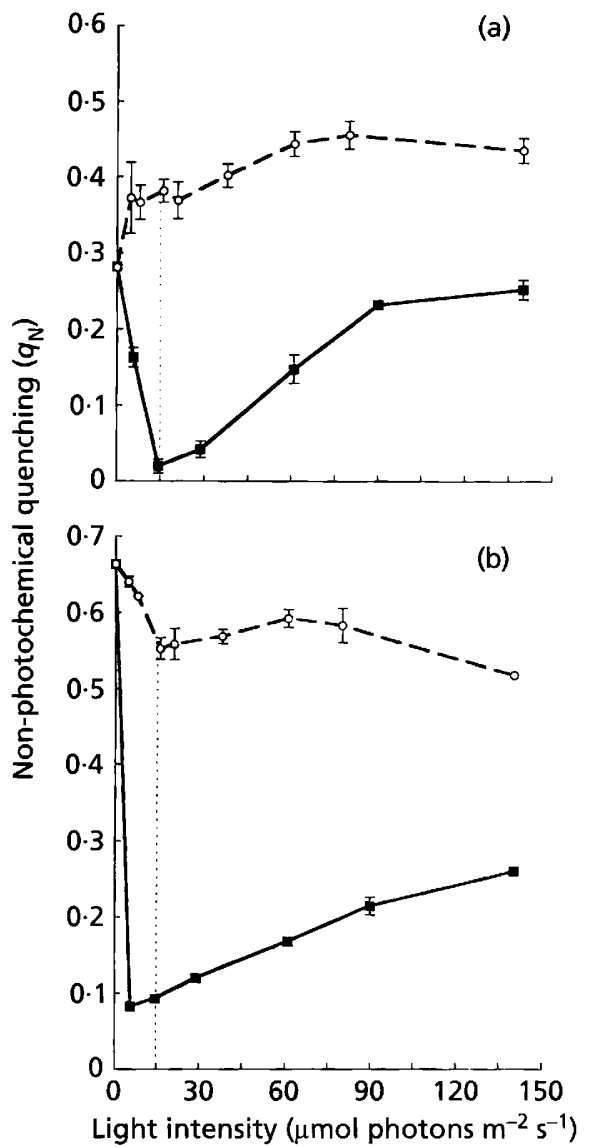

Fig. 5. Light response curves of non-photochemical quenching measured under red (- - ) or green $\left(--\mathrm{O}_{--}\right)$light. The dashed vertical line marks the growth light intensity $(15 \mu \mathrm{mol}$ photons $\left.\mathrm{m}^{-2} \mathrm{~s}^{-1}\right)$. The results are means of three measurements on the same culture, \pm SE. (a) Culture grown under red light; (b) culture grown under green light.

optical properties in the filamentous Calotbrix 7601, is unknown.

Cells pre-incubated in the dark are in state II, with relatively low PS II and phycobilisome fluorescence, supporting the room-temperature fluorescence measurements which showed high non-photochemical quenching of PS II fluorescence (Fig. 5). Upon illumination with green light, PS I fluorescence increased somewhat but PS II fluorescence increased only very slightly (Fig. 6), since as also shown by Fig. 5, the cells remained in state II under green light. Under red illumination, PS I fluorescence fell and PS II fluorescence increased very significantly (Fig. 6), reflecting the transition to state I. Phycobilisome fluorescence increased above the dark-acclimated level under both green and red light, by approximately the same extent.

Fig. 7 presents further evidence that the cells strongly modulate energy flow from the phycobilisome to PS I depending on the light environment. Fig. 7(a) plots PS I fluorescence at $77 \mathrm{~K}$ versus non-photochemical quenching of in vivo PS II fluorescence, $q_{\mathrm{N}}$, measured under the 


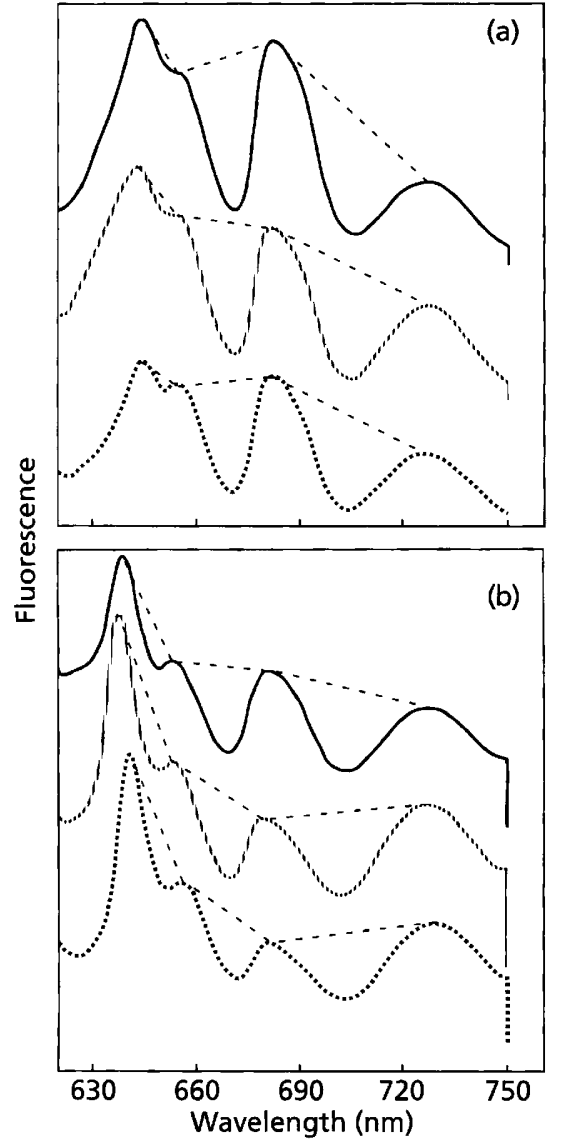

Fig. 6. $77 \mathrm{~K}$ fluorescence emission spectra for dark-incubated cells $(\cdots .$.$) , cells pre-incubated under green light ('in') and cells$ pre-incubated under red light $(\longrightarrow)$. Excitation of fluorescence was in all cases with a $574 \mathrm{~nm}$ light beam. Dashed lines emphasize changes in relative peak heights. (a) Culture grown under red light; (b) culture grown under green light.

same treatment conditions. PS I fluorescence excited by phycobilisome absorbance of light at $574 \mathrm{~nm}$ increased with increasing $q_{\mathrm{N}}$. This shows that the changes in $q_{\mathrm{N}}$ measured in living cells result from modulation of the excitation flow from the phycobilisome to PS I. In contrast, PS I fluorescence excited by chlorophyll absorbance of light at $430 \mathrm{~nm}$ declined slightly as $q_{\mathrm{N}}$ increased. Fig. 7(b) plots the ratio (PS I fluorescence excited by phycobilisome absorbance)/(PS I fluorescence excited by chlorophyll absorbance) versus $q_{\mathrm{N}}$. As $q_{\mathrm{N}}$ increases, energy flow from the phycobilisome to PS I becomes more important relative to energy flow from chlorophyll to PS I.

\section{DISCUSSION}

CCA to red or green light results in cells with very different absorbance spectra, but the same initial slope of oxygen evolution versus light intensity, and, therefore, the same quantum yield of photosynthetic electron transport. Transfer to the alternative light lowers the quantum yield to about $60 \%$ of the acclimated level. This drop occurs because the cells have reduced ability to
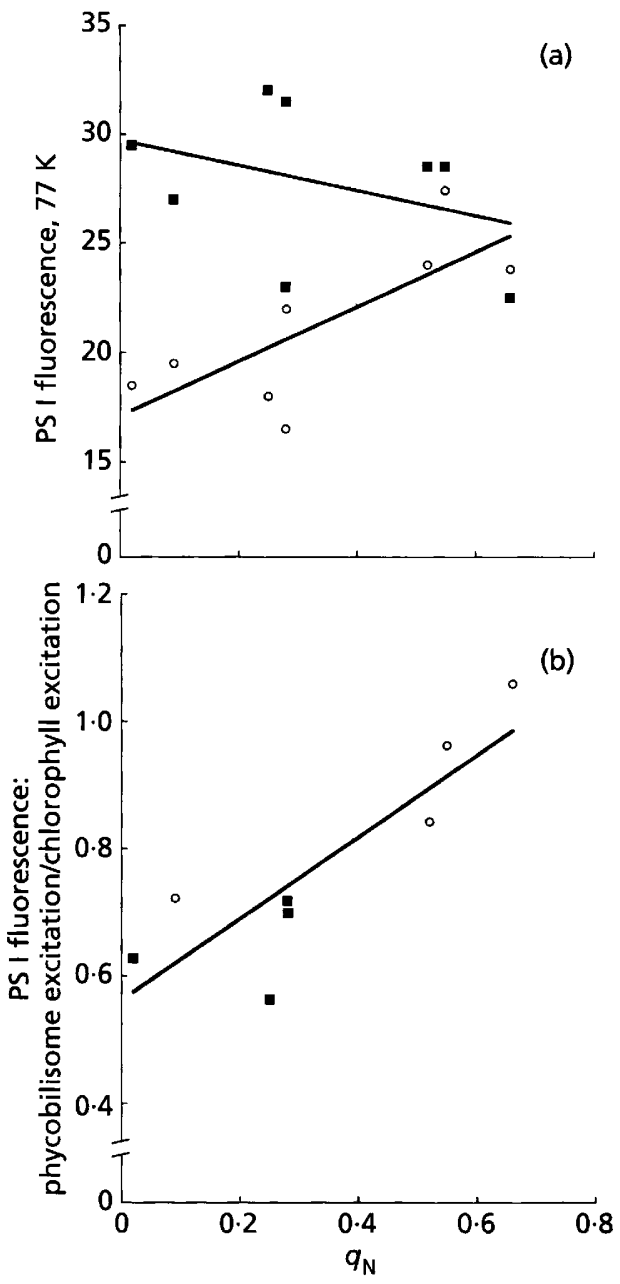

Fig. 7. PS I fluorescence emission at $77 \mathrm{~K}$ correlates with nonphotochemical quenching of in vivo PS II fluorescence. (a) PS I fluorescence excited by phycobilisome absorbance (O) $(574 \mathrm{~nm})$ or by chlorophyll absorbance ( $\boldsymbol{\square})(430 \mathrm{~nm})$, plotted versus nonphotochemical quenching of in vivo PS II fluorescence. (b) Ratio of (PS I fluorescence excited by phycobilisome absorbance)/(PS I fluorescence excited by chlorphyll absorbance), plotted versus non-photochemical quenching of in vivo PS II fluorescence. $O$. Green light cultures; $\square$, red light cultures.

capture photons in the new wavelength range and it represents the maximum effect of CCA on overall electron transport. Such a large change in quantum yield is of considerable importance for cells growing under low light. CCA in cyanobacteria is probably a special means to increase light capture in species which frequently encounter low, and chromatically imbalanced, light (Wyman \& Fay, 1987), particularly in filamentous species such as Calothrix which naturally occur in dense layers with steep gradients of light intensity and quality (Villbrandt $e t$ al., 1990). Examination of the spectra of the light sources and the whole-cell spectra shows that only phycoerythrin is able to capture the green light range. Therefore, a mechanism exists to allow green light captured by phycoerythrin alone to drive photochemistry in both photosystems (Fujita et al., 1994; Zhao et al., 1992). 
Changes in electron transport are relevant to the regulation of differentiation in Calotbrix 7601. Shifting a culture from green to red light for several hours strongly induces hormogonium differentiation, which precedes the longer-term CCA process that changes pigment composition. The reciprocal shift of a culture from red to green light does not induce hormogonia (Damerval et al., 1991; Herdman \& Rippka, 1988), even though shifts in either direction cause a similar drop in overall electron transport. Therefore, the light effects on differentiation are not caused by changes in the rate of electron transport. Rather, the green to red light shift provokes specific imbalances in electron transport which trigger differentiation (Campbell et al., 1993).

Photochemical quenching of PS II fluorescence measures the oxidation state of PS II. If excitation of PS II exceeds electron transport away from PS II, the reaction centres tend to close and $q_{\mathrm{P}}$ drops. In Calothrix $7601 q_{\mathrm{P}}$ is somewhat lower under green light, particularly in cultures shifted from red to green light, reflecting the absorbance of green light exclusively by phycoerythrin associated largely with PS II. This preferential excitation tends to drive fractional closure of the PS II reaction centres. Nevertheless, even under strong green light, most PS II centres remain open, once again indicating that the cells are able to efficiently re-direct light energy captured by phycoerythrin, to maintain fairly balanced excitation of both photosystems (Zhao et al., 1992).

In cyanobacteria, transfer of energy from the phycobilisome/PS II supracomplex to PS I is the predominant process contributing to non-photochemical quenching of PS II fluorescence (Campbell et al., 1996). The behaviour of Calothrix 7601 grown under green light provides strong support to this interpretation. Greenlight cultures grow with a high $q_{\mathrm{N}}$, but electron transport is faster under green light than when measured under red light, where cells shift to a low $q_{\mathrm{N}}$. If the high $q_{\mathrm{N}}$ under green light reflected energy lost as heat, the overall system would be less efficient under green than red light. Instead, under green light, energy captured by the phycobilisome/ PS II is transferred to PS I, rather than being used to drive PS II photochemistry. This transfer appears as a high $q_{\mathrm{N}}$ and low PS II fluorescence, even though overall electron transport in these cells is more efficient under green light than under red light.

This energy flow can be detected directly using $77 \mathrm{~K}$ fluorescence emission from PS I. Light energy absorbed by the phycobilisome excites PS I fluorescence, and this emission increased in parallel with the $q_{\mathrm{N}}$ parameter, measured in the cells during the pre-treatment before freezing. In contrast, chlorophyll excitation of PS I fluorescence declined slightly with increasing $q_{\mathrm{N}}$. Therefore, as $q_{\mathrm{N}}$ increases, as under green light, excitation of PS I activity via phycobilisome absorbance becomes increasingly important.

The green-light cultures operating in state II demonstrate a role for phycobilisome/PS II to PS I energy transfer under steady-state growth. Cyanobacteria are generally in state II with low PS II fluorescence and high $q_{\mathrm{N}}$ in the dark and under very low light, shifting to state I with low $q_{\mathrm{N}}$ under the normal growth light. This typical pattern is found in Calothrix 7601 upon illumination with red light, which is captured by both phycocyanin and chlorophyll and can therefore directly excite both PS II and PS I. But under green illumination $q_{\mathrm{N}}$ remains high, and light captured by phycoerythrin drives both PS II and PS I photochemistry, for balanced electron transport. This strategy may also be reflected in the length of phycobilisome rods. In some strains under green light, each rod contains three hexameric discs of phycoerythrin, which under red light are replaced by only two discs of phycocyanin (Cohen-Bazire \& Bryant, 1982; Tandeau de Marsac, 1983). The longer rod under green light may reflect the increased duty of the phycobilisome serving as antenna for both PS II and, indirectly, for PS I (Zhao et al., 1992).

State transitions in cyanobacteria are regulated by the balance of electron transport between PS II and PS I (Mullineaux \& Allen, 1986; Vernotte et al., 1990), although the mechanistic details remain controversial (Fujita et al., 1994; Sidler, 1994). In this case, green-light excitation of phycoerythrin drives overexcitation of PS II, which in turn causes establishment of state II with a high flow of excitation from the phycobilisome/PS II to PS I. Calotbrix PCC 7601 thereby attains similar overall photosynthesis under either red or green light, but uses very different light-harvesting strategies to accommodate the chromatically imbalanced lights.

\section{ACKNOWLEDGEMENTS}

This work was performed in the laboratory of Professor Gunnar Öquist with funding from the Swedish Natural Science Research Council. The author thanks Professor Öquist, Dr Nicole Tandeau de Marsac, Dr Jean Houmard, Dr Amanda Cockshutt and Dr Henrik Schubert for discussions and critical reading. Calothrix sp. PCC 7601 was a kind gift from Rosmarie Rippka of the Pasteur Culture Collection.

\section{REFERENCES}

Bennett, A. \& Bogorad, L. (1973). Complementary chromatic adaptation in a filamentous blue-green alga. J Cell Biol 58, 419-435.

Bolhàr-Nordenkampf, H. R. \& Öquist, G. (1993). Chlorophyll fluorescence as a tool in photosynthesis research. In Photosynthesis and Production in a Changing Environment: a Field and Laboratory Manual, pp. 193-206. Edited by D. O. Hall, J. M. O. Scurlock, H. R. Bolhàr-Nordenkampf, R. C. Leegood \& S. P. Long. London: Chapman \& Hall.

Campbell, D. A., Houmard, J. \& Tandeau de Marsac, N. (1993). Electron transport regulates cellular differentiation in the filamentous cyanobacteria Calothrix. Plant Cell 5, 451-463.

Campbell, D., Bruce, D., Carpenter, C., Gustafsson, P. \& Öquist, G. (1996). Two forms of the photosystem II D1 protein alter energy dissipation and state transitions in the cyanobacterium Synechococcus sp. PCC 7942. Photosynth Res (in press).

Capuano, V., Mazel, D., Tandeau de Marsac, N. \& Houmard, J. 
(1988). Complete nucleotide sequence of the red-light specific set of phycocyanin genes from the cyanobacterium Calothrix PCC7601. Nucleic Acids Res 16, 1626.

Clarke, A. K., Hurry, V. M., Gustafsson, P. \& Öquist, G. (1993). Two functionally distinct forms of the photosystem II reactioncenter protein D1 in the cyanobacterium Synechococcus. Proc Natl Acad Sci USA 90, 11985-11989.

Clarke, A. K., Campbell, D., Gustafsson, P. \& Öquist, G. (1995). Dynamic responses of photosystem II and phycobilisomes to changing light in the cyanobacterium Synechococcus sp. PCC 7942. Planta 197, 553-562.

Cohen-Bazire, G. \& Bryant, D. A. (1982). Phycobilisomes: composition and structure. In The Biology of Cyanobacteria, pp. 143-190. Edited by N. G. Carr \& B. A. Whitton. Oxford: Blackwell Scientific Publications.

Damerval, T., Guglielmi, G., Houmard, J. \& Tandeau de Marsac, N. (1991). Hormogonium differentiation in the cyanobacterium Calothrix: a photoregulated developmental process. Plant Cell 3, 191-201.

Dring, M. J. (1981). Chromatic adaptation of photosynthesis in benthic marine algae: an examination of its ecological significance using a theoretical model. Limnol Oceanogr 26, 271-284.

Dring, M. J. (1990). Light harvesting and pigment composition in marine phytoplankton and macroalgae. In Light and Life in the Sea, pp. 89-103. Edited by P. J. Herring, A. K. Campbell, M. Whitfield \& L. Maddock. Cambridge: Cambridge University Press.

Dring, M. J., Schmid, R. \& Luning, K. (1996). Influence of blue light, UV-B radiation and tidal phasing on seaweed photosynthesis in sublittoral coastal ecosystems. In Photosynthesis: from Light to Biosphere V, pp. 749-754. Edited by P. Mathis. Dordrecht: Kluwer.

Erokhina, L. G. (1992). Spectral effects of chomatic adaptation of nitrogen-fixing cyanobacteria growing on different nitrogen sources. Microbiology (English translation of Mikrobiologiya) 61, 673-679.

Fujita, Y. \& Hattori, A. (1960). Effect of chromatic lights on phycobilin formation in a blue-green alga Tolypothrix tenuis. Plant Cell Pbysiol 1, 293-303.

Fujita, Y., Murakami, A., Aizawa, K. \& Ohki, K. (1994). Short-term and long-term adaptation of the photosynthetic apparatus: homeostatic properties of thylakoids. In The Molecular Biology of Cyanobacteria, pp. 677-692. Edited by D. A. Bryant. Dordrecht: Kluwer.

Gendel, S., Ohad, I. \& Bogorad, L. (1979). Control of phycoerythrin synthesis during chromatic adaptation. Plant Physiol 64, 786-790.

Grossman, A. R. (1990). Chromatic adaptation and the events involved in phycobilisome biosynthesis. Plant Cell Environ 13, 651-666.

Grossman, A. R., Lemaux, P. G., Conley, P. B., Bruns, B. U. \& Anderson, L. K. (1988). Characterization of phycobiliprotein and linker polypeptide genes in Fremyella diplosiphon and their regulated expression during complementary chromatic adaptation. Photosynth Res 17, 23-56.

Grossman, A. R., Schaefer, M. R., Chiang, G. G. \& Collier, J. L. (1994). The responses of cyanobacteria to environmental conditions: light and nutrients. In The Molecular Biology of Cyanobacteria, pp. 677-692. Edited by D. A. Bryant. Dordrecht: Kluwer.

Hattori, A. \& Fujita, Y. (1959a). Formation of phycobilin pigments in a blue-green alga, Tolypothrix tenuis, as induced by illumination with coloured lights. J Biochem (Tokyo) 46, 521-524.

Hattori, A. \& Fujita, Y. (1959b). Effect of pre-illumination on the formation of phycobilin pigments in a blue-green alga, Tolypotbrix tenuis. J Biochem (Tokyo) 46, 1259-1261.
Herdman, M. \& Rippka, R. (1988). Cellular differentiation: hormogonia and baeocytes. Methods Enzymol 167, 232-242 and 851-853 (Addendum).

Houmard, J., Schyns, G., Jia, L., Sobczyck, A., Liotenberg, S., Campbell, D. \& Tandeau de Marsac, N. (1996). Molecular factors that control gene expression in a filamentous cyanobacterium. In Photosynthesis: from Light to Biosphere III, pp. 433-438. Edited by P. Mathis. Dordrecht: Kluwer.

Kehoe, D. \& Grossman, A. (1996). The use of site-directed mutagenesis in the analysis of complementary chromatic adaptation. In Photosynthesis: from Light to Biosphere III, pp. 501-504. Edited by P. Mathis. Dordrecht: Kluwer.

van Kooten, O. \& Snel, J. F. H. (1990). The use of chlorophyll fluorescence nomenclature in plant stress physiology. Photosynth Res $25,147-150$.

Krause, G. H. \& Weis, E. (1991). Chlorophyll fluorescence and photosynthesis: the basics. Annu Rev Plant Physiol Plant Mol Biol 42, 313-349.

Liotenberg, S., Campbell, D., Rippka, R., Houmard, J. \& Tandeau de Marsac, N. (1996). Effect of the nitrogen source on phycobiliprotein synthesis and cell reserves in a chromatically adapting filamentous cyanobacterium. Microbiology 142, 611-622.

Mazel, D., Guglielmi, G., Houmard, J., Sidler, W., Bryant, D. A. \& Tandeau de Marsac, N. (1986). Green light induces transcription of the phycoerythrin operon in the cyanobacterium Calotbrix 7601. Nucleic Acids Res 14, 8279-8290.

Mullineaux, C. W. \& Allen, J. F. (1986). The state 2 transition in the cyanobacterium Synecbococcus 6301 can be driven by respiratory electron flow into the plastoquinone pool. FEBS Lett 205, 155-160.

Oelmüller, R., Conley, P. B., Federspiel, N., Briggs, W. R. \& Grossman, A. R. (1988a). Changes in accumulation and synthesis of transcripts encoding phycobilisome components during acclimation of Fremyella diplosiphon to different light qualities. Plant Physiol 88, 1077-1083.

Oelmüller, R., Grossman, A. R. \& Briggs, W. R. (1988b). Photoreversibility of the effect of red and green light pulses on the accumulation in darkness of mRNAs coding for phycocyanin and phycoerythrin in Fremyella diplosiphon. Plant Pbysiol 88, 1084-1091.

Ögren, E. \& Öquist, G. (1984). Photoinhibition of photosynthesis in Lemna gibba as induced by the interaction between light and temperature. II. Photosynthetic electron transport. Physiol Plant 62, 187-192.

Öquist, G., Campbell, D., Clarke, A. K. \& Gustafsson, P. (1995). The cyanobacterium Synechococcus modulates PS II function in response to excitation stress through D1 exchange. Photosynthesis Research 46, 151-158.

Rippka, R. \& Herdman, H. (1992). Pasteur Culture Collection of Cyanobacterial Strains in Axenic Culture, vol. I, Catalogue of Strains. Paris: Institut Pasteur.

Rippka, R., Deruelles, J., Waterbury, J. B., Herdman, M. \& Stanier, R. Y. (1979). Generic assigments, strain histories and properties of pure cultures of cyanobacteria. J Gen Microbiol 111, 1-61.

Salehian, O. \& Bruce, D. (1992). Distribution of excitation energy in photosynthesis: quantification of fluorescence yields form intact cyanobacteria. J Lumin 51, 91-98.

Schmidt-Goff, C. M. \& Federspiel, N. A. (1993). In vivo and in vitro footprinting of a light-regulated promoter in the cyanobacterium Fremyella diplosiphon. J Bacteriol 175, 1806-1813.

Schyns, G., Sobczyk A., Tandeau de Marsac, N. \& Houmard, J. (1994). Specific initiation of transcription at a cyanobacterial promoter with RNA polymerase purified from Calothrix sp. PCC 7601. Mol Microbiol 13, 887-896. 
Sidler, W. (1994). Phycobilisome and phycobiliprotein structures. In The Molecular Biology of Cyanobacteria, pp, 139-216. Edited by D. A. Bryant. Dordrecht: Kluwer.

Sobczyk, A., Schyns, G., Tandeau de Marsac, N. \& Houmard, J. (1993). Transduction of the light signal during complementary chromatic adaptation in the cyanobacterium Calotbrix sp. PCC 7601: DNA-binding proteins and modulation by phosphorylation. EMBO J 12, 997-1004.

Sobczyk, A., Bely, A., Tandeau de Marsac, N. \& Houmard, J. (1994). A phosphorylated DNA-binding protein is specific for the red-light signal during complementary chromatic adaptation in cyanobacteria. Mol Microbiol 13, 875-885.

Tandeau de Marsac, N. (1983). Phycobilisomes and complementary chromatic adaptation in cyanobacteria. Bull Inst Pasteur 81, 201-254.

Tandeau de Marsac, N. \& Houmard, J. (1988). Complementary chromatic adaptation: physiological conditions and action spectra. Methods Envymol 167, 318-328.

Tandeau de Marsac, N. \& Houmard, J. (1993). Adaptation of cyanobacteria to environmental stimuli: new steps towards molecular mechanisms. FEMS Microbiol Rev 104, 119-190.

Tandeau de Marsac, N., Mazel, D., Damerval, T., Guglielmi, G.,
Capuano, V. \& Houmard, J. (1988). Photoregulation of gene expression in the filamentous cyanobacterium Calothrix sp. PCC7601: light-harvesting complexes and cell differentiation. Photosynth Res 18, 99-132.

Vernotte, C., Astier, C. \& Olive, J. (1990). State 1-state 2 adaptation in the cyanobacteria Synechocystis PCC 6714 wild type and Synechocystis PCC 6803 wild type and phycocyanin-less mutant. Photosynth Res 26, 203-212.

Villbrandt, M., Stal, L. J. \& Krumbein W. E. (1990). Interactions between nitrogen fixation and oxygenic photosynthesis in a marine cyanobacterial mat. FEMS Microbiol Ecol 74, 59-72.

Wyman, M. \& Fay, P. (1987). Acclimation to the natural light climate. In The Cyanobacteria, pp. 347-376. Edited by P. Fay \& C. van Baalen. Amsterdam: Elsevier.

Zhao, J., Zhou, J. \& Bryant, D. A. (1992). Energy transfer processes in phycobilisomes as deduced from analyses of mutants of Synechococcus sp. PCC 7002. In Research in Photosynthesis, vol. 1, pp. 25-32. Edited by N. Murata. Dordrecht: Kluwer.

Received 14 September 1995; revised 8 January 1996; accepted 16 January 1996. 